\title{
SUSTAINABLE CARDBOARD LABEL PRODUCTION
}

\author{
Gulsah Yilan ${ }^{1}$ (D), Arif Ozcan $^{2}$ (D), Tanju Caglar ${ }^{3}$ \\ ${ }^{1}$ Marmara University, Faculty of Engineering, Chemical Engineering, Istanbul, Turkey \\ ${ }^{2}$ Marmara University, School of Applied Sciences, Printing Technologies, Istanbul, Turkey \\ ${ }^{3}$ Marmara University, Institute of Pure and Applied Sciences, Printing Technologies, \\ Istanbul, Turkey
}

\begin{abstract}
Recently, all industrial sectors have shown significantly increasing attention in reaching the sustainability goals regarding economic, environmental, social, and also technological aspects not only at the regional level but also nationwide and even global scale. Aside from being an economically popular concept, sustainability is strictly related to effective resource use and efficient waste disposal. Thus, it functions as a complementary issue to be considered in various production activities. The sustainable production approach includes reducing or (if possible) eliminating the negative impacts on the human health and environment, reducing the waste generated, increasing the recycling rate, and developing energy and material saving processes. The printing industry is one of the most important industries in reaching sustainable production goals. The need for the printed products, which is the focus of this study, is increasing in parallel with the changing consumer expectations and technological developments. However, from the point of the printing industry view, a solid sustainability consensus is not settled among the practitioners, yet. This study aims to evaluate the sustainability of the cardboard label production considering several combinations of raw materials such as paper, ink, and surface coating additives via appropriate MultiCriteria Decision Analysis (MCDA) methods. The most frequently used paper and ink types are considered with three alternatives for each. To indicate the sustainability scores economic, environmental, and social evaluation criteria are selected. By applying the Multi-Attribute Utility Theory (MAUT), the sustainability score of each label is calculated to determine the optimum alternative in terms of the production process and also the material used. This evaluation provides detailed information to the producer and also to the consumer about the alternative production routes to use less energy and raw material, and also to decrease the environmental impacts while sustaining the economic feasibility. Besides, alternative solutions are offered to reach sustainability goals by considering the economic and environmental life cycle impacts of these materials. Hence, an increase in awareness about the printing industry and service channels is expected. Moreover, this study is also important in presenting the applicability of sustainability assessments in the printing industry.
\end{abstract}

Keywords: Sustainability, Printing Industry, Label Production, Multi-Criteria Decision Analysis, Case Study

\section{INTRODUCTION}

Global warming and climate change issues have been the biggest challenges of the 21st century, so far. Companies struggle with not only how to reduce their expenses but also how to sustain the balance of nature concerning technological developments. Impacts on the environment are threatening both today's and tomorrow's populations. Thus, a comprehensive perspective is required to handle global warming, industrialization, overexploitation of the natural resources, and environmental pollution issues together for offering a sustainable pathway for future generations. When the sustainability issue is discussed, one can only imagine the environmental aspects. However, sustainable development includes all related topics such as quality and quantity of goods and services produced and used by communities, perceptions of consumers and producers, poverty, environmental sensitivity, and so on. If economic and ecological balance are considered complementary aspects, then more realistic sustainability goals can be achieved to enhance the well-being of the society from social, economic, and cultural points of view (Akdoğan and Hicyorulmaz, 2015). The companies principally focus on the materials that have significant impacts on natural ecosystems when transformed or consumed. While depleting the raw materials directly or indirectly, almost all producers generate and release a variety of waste types to the environment that in turn threaten the survival of our species and also our planet. The consequences of our acts on the environment today will determine the world the next generations will be living in. The mutual thinking of creating a sustainable world continues to unite humankind (Wondemu, 2011).

Sustainability covers reducing (and if possible eliminating) the impacts of production activities on humanity and the environment, decreasing the amount of waste generated during production, increasing the 
recyclability of products, and developing production processes that aim material and energy savings. Nonetheless, sustainable development is defined as the "development that meets the needs of the present without compromising the ability of future generations to meet their own needs" (Dresner, 2008).

Fundamentally, three main goals of sustainability are reducing, reusing, and recycling waste streams. One of the most important industries in reaching sustainability goals is the printing industry that contributes significantly to the economic growth of countries (Hami et al, 2018). Considering the printing industry, the reduction in the number of waste streams results in a decrease in the raw material supply. Besides, the increased amount of reuse results in lower levels of recycling activities. The main raw materials of this market are paper, cardboard, and ink. Despite the developments in digital technologies and emerging digital communication alternatives, the demand for printed products continues increasing with changing consumer expectations. In the light of technological developments in the printing industry, the production efficiency is increasing and wastage rates are decreasing. In addition, the supply chain system - including the raw material supply, the fair use of resources, paper recycling, acquisition of raw materials for ink, and ink production - is getting more attention currently.

Cardboard label production is one of the main branches of the printing industry. The volume of production, the range of application areas, and the currency of the cardboard label production are in an increasing trend. Cardboard label produced via offset printing is one of the products with the highest market share in the label sector. It has a vital role especially in the textile sector, functioning in strengthening the image of the firm, and informing the consumers. Cardboard label designs are products with wide circulation in printing activities. The printing sector brings together the companies of raw material suppliers, cardboard label producers, and textile firms using cardboard labels in their products. Considering the limited availability of the earth's resources, it is important to prefer using environmentally friendly alternatives for the basic raw materials of paper and ink during the production activities. Nevertheless, from environmental and economic points of view, this perspective holds the keys to reduce the raw material and energy demand, to decrease the costs of raw materials, and even to open a window of opportunity for new employment possibilities in the recycling sector.

Moreover, the printing ink producers are also making a great effort in using raw materials with low (and none if possible) environmental impacts during the production of pigments, colorants, solvents, and other additives. Recently, the amounts of petroleum-based mineral oils are decreasing in response to the increase in vegetable oils. Similarly, an increasing effort is made for reducing (and eliminating if possible) the volatile organic compounds (VOCs) emissions in the solvents, drying agents, cleaning solvents, and other chemicals used in different stages of printing. A significant development is achieved in reducing and eliminating the use of IPA in the offset printing dampening solution (Ozcan, 2017).

For sustainable development, the production rate of paper and cardboard from industrial woods is increasing progressively. Additionally, there are some other approaches of sustainability such as preventing the cutting down of forests via paper production from alternative plants, naturally growing herbs, agricultural and industrial residuals (Karlovits et al, 2020), and also acid and chlorine-free bleaching process in the paper production (Masod and Abdullah, 2015). Especially Scandinavian countries are the pioneers of green technologies with low-chlorine pulp, elemental chlorine-free (ECF), and total chlorine free (TCF) bleaching techniques (Bergquist and Söderholm, 2015; Söderholm et al, 2017). Furthermore, the use of paper and paper products with chlorine is proved to create some health issues, and accordingly, the use of these products in food packaging and hygiene products is not recommended (Shoham et al, 1992).

Some printing houses in the printing industry aim to increase awareness with their individual activities employing sustainable alternatives. Small improvements in the basic principles such as product design, graphic design, paper selection, ink choosing, and even the number of colors may result in significant variations in terms of sustainability. In the process of the selection of the type of paper, ink, and coating materials to be used in the cardboard label production, proposing an alternative production route considering environmental aspects and ecological limits along with the costs may create a significant impact on the perception of consumer and producer (Monteiro et al, 2019). Thus, a transition to more sustainable production models (e.g. less deforestation, less environmental impacts, lower carbon and water footprint, lower energy demand) may be provided. The increase in efficiency as an obvious result of sustainable practices may also encourage the other stakeholders to shift from their conventional production activities to more sustainable ones.

When performing a sustainability analysis, it is vital to plot the 'big picture' i.e. rather than focusing on a single parameter, one should consider a variety of parameters simultaneously. For example, the term "water-based" is accepted as an environmentally friendly alternative, and similarly, "vegetable oil-based systems" may be considered favorable owing to the renewable source content. Nonetheless, vegetable oil- 
based products sometimes need significantly more energy to dry than alternative materials. In reality, no single technology or printing process provides the best solution. The most appropriate option can only be identified by considering all stakeholders involved in a particular process or product, taking all the relevant factors into account (Eupia, 2013).

Several modeling approaches may be used to propose a sustainability assessment. The most used methodologies are Life Cycle Assessment (LCA), Cost-Benefit Analysis (CBA), and Multi-Criteria Decision Analysis (MCDA). Especially, MCDA is the most popular method since it allows the practitioners to evaluate economic, technical, environmental, and social aspects simultaneously (Strantzali and Aravossis, 2016; Yilan et al, 2020).

In this study, an application of MCDA methodology is conducted in the label printing industry. At first, the raw materials are selected for printing as paper and ink. Then evaluation criteria are determined and valuated. The next step is to normalize the criteria so that they have the same order. A final weighting step via Multi-Attribute Utility Theory (MAUT) is applied to reach the final representative sustainability scores.

\section{METHODS}

The aim of this study is to conduct a sustainability analysis of cardboard label production with offset printing systems. In this study, several combinations of raw materials, especially paper and ink, are examined via appropriate MCDA methods. The paper and ink types are considered with three alternatives for each resulting in a number of 9 label combinations. The technical properties of the selected paper and ink types are given in tables 1 and 2, respectively.

Table 1: Physical and optical characteristics of the paper types used in the study

\begin{tabular}{|c|c|c|c|c|c|}
\hline & & & $\begin{array}{l}\text { Paper } 1 \\
\text { (0\% Recycled) }\end{array}$ & $\begin{array}{l}\text { Paper } 2 \\
\text { (25\% Recycled) }\end{array}$ & $\begin{array}{l}\text { Paper } 3 \\
\text { (50\% Recycled) }\end{array}$ \\
\hline \multicolumn{2}{|c|}{ Basis Weight $\left(\mathrm{g} / \mathrm{m}^{2}\right)$} & ISO 536:2012 & 300 & 300 & 300 \\
\hline \multicolumn{2}{|c|}{ ISO Brightness D65 (\%) } & ISO 2470-2:2008 & 105 & 104 & 104 \\
\hline \multicolumn{2}{|c|}{ Opacity (\%) } & ISO 2471:2008 & 99.8 & 99.7 & 99.9 \\
\hline \multicolumn{2}{|c|}{$\begin{array}{l}\text { Roughness Bendtsen } \\
\text { (ml/min) }\end{array}$} & ISO 8791-2:2013 & 250 & 250 & 249 \\
\hline \multicolumn{2}{|c|}{ Thickness $(\mu \mathrm{m})$} & ISO 534:2005 & 328 & 327 & 328 \\
\hline & $\mathrm{L}^{*}$ & \multirow{3}{*}{$\begin{array}{l}\text { ISO 5631-3:2014 } \\
\text { (D50/2 })\end{array}$} & 94.1 & 94.6 & 94.3 \\
\hline & $a^{*}$ & & 2.5 & 2.7 & 2.3 \\
\hline & $\mathrm{b}^{*}$ & & -7.0 & -6.7 & -7.1 \\
\hline \multicolumn{3}{|c|}{ CIE Whiteness (\%) } & 149 & 148 & 148 \\
\hline
\end{tabular}

Table 2: Physico-chemical composition of ink types used in the study

\begin{tabular}{|c|c|c|c|}
\hline & $\begin{array}{c}\text { Ink 1 (Soy } \\
\text { oil-based) }\end{array}$ & $\begin{array}{c}\text { Ink 2 (Mineral } \\
\text { oil-based) }\end{array}$ & $\begin{array}{c}\text { Ink 3 (UV } \\
\text { curable ink) }\end{array}$ \\
\hline Pigment & 20 & 20 & 20 \\
\hline Resin & 30 & 30 & 0 \\
\hline Mineral oils & 0 & 0 & 0 \\
\hline Vegetable oils & 40 & 40 & 0 \\
\hline Dryers & 5 & 5 & 0 \\
\hline Additives & 5 & 5 & 5 \\
\hline Oligomer & 0 & 0 & 50 \\
\hline Monomer & 0 & 0 & 20 \\
\hline Photoinitiator & 0 & 0 & 5 \\
\hline
\end{tabular}


The widely accepted methodology for conducting a sustainability analysis is the MCDA technique. In this study, a techno-economic and eco-social parameter are selected as cost and volatile organic compounds (VOCs), respectively. No extra technical parameter is required since the recyclable content of the paper is considered in the cost and VOC calculations.

As usual, techno-economic parameters have always been the main drivers of decision-makers. However, as environmental awareness is increased in response to the sustainability debate, the need for additional parameters emerged for decision-making. In this respect, the VOCs parameter is selected as an eco-social parameter. VOCs have several negative environmental effects and have been tied to adverse health effects for those with prolonged exposure. Traditional inks are petroleum-based and are known to release high amounts of VOCs while vegetable-based inks, usually made with soy, are more sustainable and release no VOCs (Merritt, 2020).

It is reported that petroleum-based inks emit approximately $25 \%$ to $40 \%$ of VOCs while drying, while the emissions levels of vegetable inks (such as soy, flax, canola, or safflower) can be as low as $2 \%$ to $4 \%$, even some brands of ink releasing none at all. Current regulations limit the allowed VOCs release rates for petroleum inks to be no more than 30 percent VOC, and this is where the new vegetable-based inks can be an effective green alternative (Moore, 2013; Stone, 2008).

\section{RESULTS AND DISCUSSION}

The calculation results of the selected paper and ink types are given in table 3. Paper types are based on the widely used coated freesheet paper differentiating in the recycled content from 0 to $50 \%$. Ink types are selected as UV curable ink, soy-based ink, and mineral-based ink. The techno-economic criterion, cost of paper and ink types, is evaluated directly from the sales department of a private company. The eco-social criterion is evaluated with an online calculator (Environmental Paper Network's Paper Calculator) (https://c.environmentalpaper.org/) for the paper types and from literature for the ink types.

Table 3: Evaluation criteria used in the study

\begin{tabular}{|c|c|c|}
\hline & $\begin{array}{c}\text { Techno-Economic } \\
\text { Cost }(\boldsymbol{\epsilon} / \mathrm{kg})\end{array}$ & $\begin{array}{c}\text { Eco-social } \\
\text { VOC (kg/ton) }\end{array}$ \\
\hline Paper types & & \\
\hline P1 (Coated freesheet, recycled content: 0\%) & 3.0 & $4.05 \mathrm{E}-02$ \\
\hline P2 (Coated freesheet, recycled content: $25 \%)$ & 2.7 & $3.87 \mathrm{E}-02$ \\
\hline P3 (Coated freesheet, recycled content: 50\%) & 2.5 & $3.69 \mathrm{E}-02$ \\
\hline Ink types & & \\
\hline I1 (UV curable ink) & 10 & $0.00 \mathrm{E}+00$ \\
\hline I2 (Soy-based ink) & 4.5 & $4.00 \mathrm{E}-02$ \\
\hline I3 (Mineral-based) & 4.0 & $3.00 \mathrm{E}-01$ \\
\hline
\end{tabular}

According to the different paper and ink types, a combination of 9 labels (see Figure 1 for label content) is compared from a sustainable point of view with an MCDA technique. At first, the total cost and total VOCs are calculated considering $98 \%$ of the label is made of paper and the rest $2 \%$ is made up of ink. While the paper and ink types are varying, we choose a constant type of varnish for fixing the number of labels to 9. Since all labels have the same varnish, the effects related to varnish do not make a difference across different alternatives. For this reason, the effects of varnish are not included in the analysis. After calculating the total values of cost and VOCs, the normalization process is evaluated in such a way that the values differ from 0 (the worst option) to 1 (the best option). The normalization step is especially important in setting a common basis for parameters with different numerical values and also units. After normalization, the parameters can be combined to reach a final sustainability score. In this study, an equal weighting is preferred for techno-economic and eco-social parameters to calculate a representative score in the application of MAUT. 


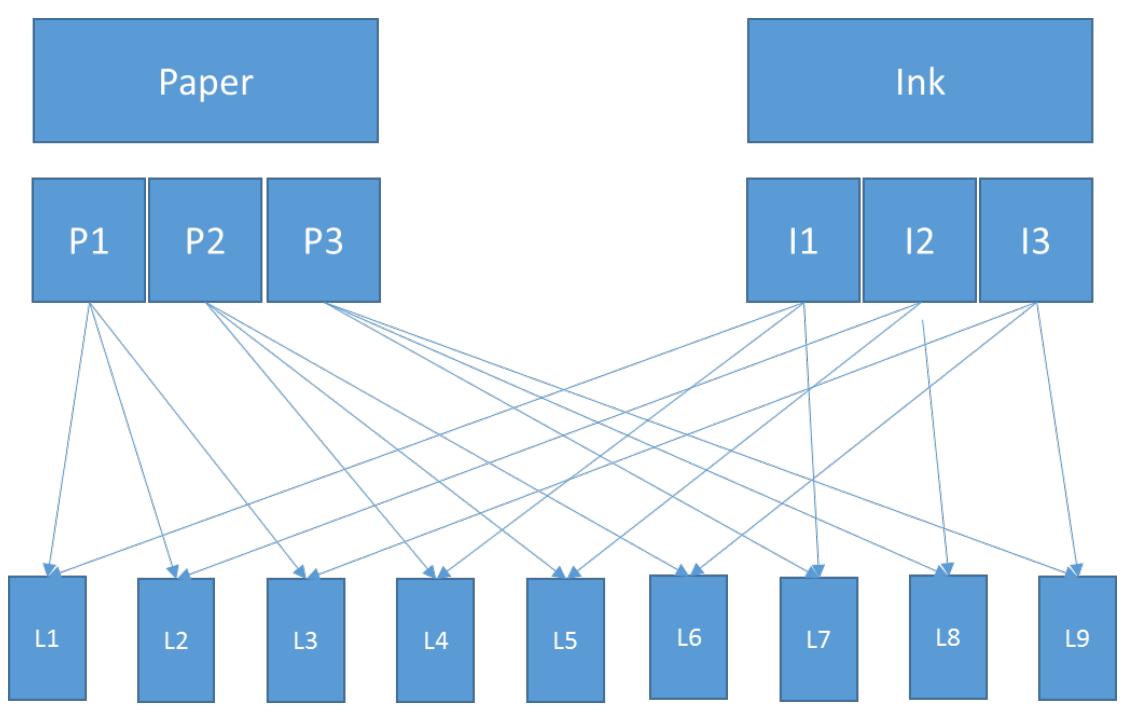

Figure 1: Combinations of paper and ink types used in the study

The normalized values of cost and VOCs along with the sustainability scores are given in Figure 2. Orange and grey bars represent the normalized values of cost and VOCs, respectively. As mentioned before, the higher the normalized values, the better the sustainability scores. Blue bars represent the cumulative scores with the equal weight (50\% cost and 50\% VOCs), and finally indicate sustainability. As seen in the figure, L9 has the lowest cost (meaning the highest normalized value) while L7 has the lowest VOCs.

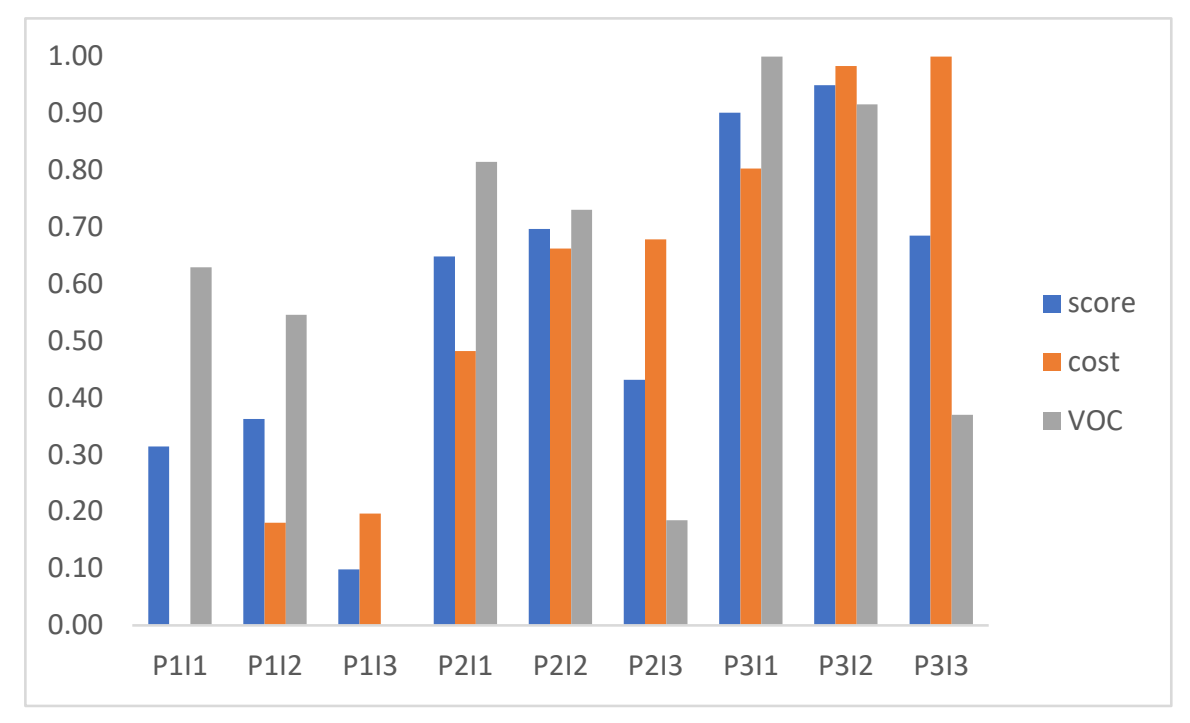

Figure 2: Sustainability scores of each label used in this study

A final ranking of the sustainability scores in decreasing order from the best to the worst option is given in table 4 . The highest cumulative score in terms of sustainability is gathered for $L 8$ indicating the best option where $L 3$ is the worst option. The results clearly show that the decision-makers require a broader perspective to select the most sustainable option among different alternatives rather than evaluating single aspects.

Table 4: A final ranking of the sustainability score of each label used in this study

\begin{tabular}{|l|c|c|c|c|c|c|c|c|c|}
\hline Ranking & 1 (Best) & 2 & 3 & 4 & 5 & 6 & 7 & 8 & 9 (Worst) \\
\hline Label & L8 & L7 & L5 & L9 & L4 & L6 & L2 & L1 & L3 \\
\hline Content & P3I2 & P3I1 & P2I2 & P3I3 & P2I1 & P2I3 & P1I2 & P1I1 & P1I3 \\
\hline
\end{tabular}




\section{CONCLUSIONS}

The printing industry is one of the most important industries in reaching sustainable production goals. However, a solid sustainability consensus is not settled among the practitioners, yet. In this study, the sustainability scores of a total number of 9 labels are calculated to determine the optimum alternative via MCDA methodology. The evaluation criteria are selected as cost and VOCs. The optimum results acquired with neither the cheapest (L9) nor the environmentally friendly (L7) alternative, rather a distinct label (L8) has the highest score indicating the need for a broader perspective to offer a sustainable alternative among the similar options.

\section{ACKNOWLEDGMENTS}

The study is held as a part of the Master Thesis entitled as "Sustainability in Printing Industry: A Study on Cardboard Label Production", to be submitted to Marmara University, the Institute of Pure and Applied Sciences.

\section{REFERENCES}

[1] Akdoğan, H., Hicyorulmaz, E.: "The importance of the sustainability of environmental accounting", Journal of Economic Development, Environment and People 4 (2), 6-20, 2015. doi: 10.26458/jedep.v4i2.104

[2] Bergquist, A. K., Söderholm, K.: "Transition to greener pulp: regulation, industry responses and path dependency", Business History 57 (6), 862-884, 2015. doi: 10.1080/00076791.2014.986105

[3] Dresner, S.: "The principles of sustainability" (Earthscan, Sterling VA, 2008.)

[4] Eupia, "Information note: Environmental impact of printing ink", URL: https://www.eupia.org/fileadmin/FilesAndTradExtx_edm/2013-0305_EuPIA_Environmental_Impact_of_Printing_Inks_01.pdf (last request: 2020-09-30), 2013.

[5] Hami, N., Mat Yamin, F., Mohd Shafie, S., Muhamad, M. R.: "Implementing sustainable manufacturing practices in a printing company: A case study", The $2^{\text {nd }}$ Conference on Technology \& Operations Management $2{ }^{\text {nd }}$ CTOM (University of Science, Pulau Pinang, Malaysia, 2018.)

[6] Karlovits, I., Kavcic, U., Lavric, G., Sinkovec, A., Zoric, V.: "Digital printability of papers made from invasive plants and agro-industrial residues", Cellulose Chemistry and Technology 54 (5-6), 523-529. 2020. doi: 10.35812/CelluloseChemTechnol.2020.54.53

[7] Masod, M. Y. B., Abdullah, H.: "Practicing Environmental Protection in Printing Industry", Journal of Printing Science and Technology 52 (6), 497-499, 2015. doi: 10.11413/nig.52.497

[8] Merritt.: "4 Best Green Solutions for Sustainability in the Printing Industry", URL: https://www.josephmerritt.com/marketing-media/articles/4-best-green-solutions-for-sustainabilityin-the-printing-industry (last request 2020-09-30), 2020.

[9] Monteiro, J., Silva, F. J. G., Ramos, S. F., Campilho, R. D. S. G., Fonseca, A. M.: “Eco-Design and Sustainability in Packaging: A Survey", Procedia Manufacturing 38, 1741-1749, 2019. doi: 10.1016/j.promfg.2020.01.097

[10] Moore, V.: "Benefits Of Eco Solvent Inks", URL: https://www.sustainablebusinesstoolkit.com/benefits-of-eco-solventinks/ (last request 2020-09-30), 2013

[11] Ozcan, A.: "Examination of printability parameters of iPa free offset printing", Journal of Graphic Engineering and Design 8 (1), 29. 2017. doi: 10.24867/JGED-2017-1-029

[12] Shoham, Y., Schwartz, Z., Khasin, A., Gat, O., Zosim, Z., Rosenberg, E.: "Delignification of wood pulp by a thermostable xylanase from Bacillus stearothermophilus strain T-6", In Microorganisms to Combat Pollution, (Springer, Dordrecht, 1992.), pages 83-94. doi: 10.1007/BF00129084

[13] Söderholm, K., Bergquist, A. K., Söderholm, P.: "The transition to chlorine free pulp revisited: Nordic heterogeneity in environmental regulation and R\&D collaboration", Journal of Cleaner Production 165, 1328-1339, 2017. doi: 10.1016/j.jclepro.2017.07.190

[14] Stone, T.: "Eco-friendly inks", URL: https://creativepro.com/eco-friendly-inks/ (last request 2020-0930), 2008.

[15] Strantzali, E., Aravossis, K.: "Decision making in renewable energy investments: A review", Renewable and Sustainable Energy Reviews 55, 885-898. 2016. doi: 10.1016/j.rser.2015.11.021 
[16] Wondemu, E.: "Ink and paper saving for sustainable printing", BSc thesis, Helsinki Metropolia University of Applied Sciences Degree Programme in Media Engineering, 5-41, 2011.

[17] Yilan, G., Kadirgan, M. N., Çiftçioğlu, G. A.: "Analysis of electricity generation options for sustainable energy decision making: The case of Turkey", Renewable Energy 146, 519-529, 2020. doi: 10.1016/j.renene.2019.06.164

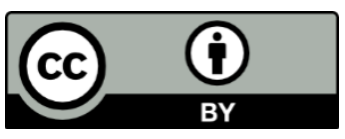

(C) 2020 Authors. Published by the University of Novi Sad, Faculty of Technical Sciences, Department of Graphic Engineering and Design. This article is an open access article distributed under the terms and conditions of the Creative Commons Attribution license 3.0 Serbia (http://creativecommons.org/licenses/by/3.0/rs/). 